\title{
The quasi 16-day wave in mesospheric water vapor during boreal winter 2011/2012
}

\author{
D. Scheiben ${ }^{1}$, B. Tschanz ${ }^{1}$, K. Hocke ${ }^{1}$, N. Kämpfer ${ }^{1}$, S. Ka ${ }^{2}$, and J. J. Oh ${ }^{2}$ \\ ${ }^{1}$ Institute of Applied Physics and Oeschger Centre for Climate Change Research, University of Bern, 3012 Bern, Switzerland \\ ${ }^{2}$ Sookmyung Women's University, Seoul 140-742, Korea \\ Correspondence to: D. Scheiben (dominik.scheiben@iap.unibe.ch)
}

Received: 15 August 2013 - Published in Atmos. Chem. Phys. Discuss.: 7 November 2013

Revised: 30 April 2014 - Accepted: 21 May 2014 - Published: 1 July 2014

\begin{abstract}
This study investigates the characteristics of the quasi 16-day wave in the mesosphere during boreal winter 2011/2012 using observations of water vapor from groundbased microwave radiometers and satellite data. The groundbased microwave radiometers are located in Seoul (South Korea, $37^{\circ} \mathrm{N}$ ), Bern (Switzerland, $47^{\circ} \mathrm{N}$ ) and Sodankylä (Finland, $67^{\circ} \mathrm{N}$ ). The quasi 16-day wave is observed in the mesosphere at all three locations, while the dominant period increases with latitude from 15 days at Seoul to 20 days at Sodankylä. The observed evolution of the quasi 16-day wave confirms that the wave activity is strongly decreased during a sudden stratospheric warming that occurred in midJanuary 2012. Using satellite data from the Microwave Limb Sounder on the Aura satellite, we examine the zonal characteristics of the quasi 16-day wave and conclude that the observed waves above the midlatitudinal stations Seoul and Bern are eastward-propagating $s=-1$ planetary waves with periods of 15 to 16 days, while the observed oscillation above the polar station Sodankylä is a standing wave with a period of approximately 20 days. The strongest relative wave amplitudes in water vapor during the investigated time period are approximately $15 \%$. The wave activity varies strongly along a latitude circle. The activity of the quasi 16-day wave in mesospheric water vapor during boreal winter 2011/2012 is strongest over northern Europe, the North Atlantic Ocean and northwestern Canada. The region of highest wave activity seems to be related to the position of the polar vortex. We conclude that the classic approach to characterize planetary waves zonally averaged along a latitude circle is not sufficient to explain the local observations because of the strong longitudinal dependence of the wave activity.
\end{abstract}

\section{Introduction}

The dynamical regime of the extratropical middle atmosphere is characterized by waves and tides, in particular by global-scale planetary waves during wintertime. Planetary waves are globally coherent oscillations whose restoring force is the latitudinal gradient of planetary vorticity (Pancheva and Mukhtarov, 2011, and references therein). Planetary waves are a transport mechanism for chemical species, energy and momentum. They are known to propagate vertically from the lower to the upper atmosphere (e.g., Charney and Drazin, 1961), but can also be generated in situ in the mesosphere and lower thermosphere (MLT) (e.g., Smith, 1996, 2003; Forbes et al., 2002). Supposedly, much of the observed spatiotemporal variability in the MLT is due to upward-propagating planetary waves (e.g., Krüger et al., 2005; Palo et al., 2005; Shepherd et al., 2007; Pancheva et al., 2008a, b).

An important class of planetary waves are Rossby waves and normal modes with periods around 2, 5, 10 and 16 days (Salby, 1981a, b). The vertical propagation of planetary waves leads to wave breaking at higher altitudes due to the decrease in air density, which in turn results in wave-meanflow interaction, which is known to be a major driver of atmospheric dynamics in the wintertime middle atmosphere (Andrews et al., 1987). Such wave-mean-flow interaction can drastically alter the zonal mean flow, e.g., during a sudden stratospheric warming (SSW), and is believed to be the main mechanism for the onset of a SSW (Matsuno, 1971). Consistently, observations have shown that the time period before the onset of a SSW is often characterized by high wave activity (e.g., Hirota et al., 1990; Sivjee et al., 1994; Jacobi et al., 2003). 
The current study investigates the quasi 16-day planetary wave in the extratropical northern mesosphere during boreal winter 2011/2012. The actual period of the quasi 16-day wave has been observed to lie between 12 and 20 days (Day et al., 2011, and references therein), which is consistent with the theory of the normal modes of traveling waves (Salby, 1981a, b). Previous studies of the quasi 16-day wave used observations of ground-based wind data from meteor and medium-frequency radars (e.g., Forbes et al., 1995; Mitchell et al., 1999; Luo et al., 2000; Day et al., 2010) and temperature and geopotential height data from satellite instruments (e.g., Day et al., 2011; Pancheva and Mukhtarov, 2011). These studies consistently show a seasonal cycle of the quasi 16-day wave activity at midlatitudes with the largest wave amplitudes occurring during wintertime. It was suggested that the mesospheric quasi 16-day wave can be transported from the winter hemisphere across the Equator to the summer hemisphere (Forbes et al., 1995; Espy et al., 1997), where vertical wave propagation from lower altitudes into the mesosphere would not be possible (Charney and Drazin, 1961). Espy et al. (1997) also suggested a modulation of the crosshemispheric transport of the quasi 16-day wave by the quasibiennial oscillation. The generation and propagation of the quasi 16-day wave is still not fully understood and further observational data are needed to improve the current understanding of the quasi 16-day wave.

In contrast to the abovementioned studies which were based on observations of geopotential height, temperature and wind, we use observations of middle-atmospheric water vapor to investigate the quasi 16-day wave during winter $2011 / 2012$. This winter was characterized by strong wave activity and a sudden stratospheric warming during midJanuary 2012. Since middle-atmospheric water vapor has a long photochemical lifetime, it can be used as a tracer to study atmospheric dynamics, as long as there are vertical and/or horizontal gradients in water vapor. Observations from ground-based microwave radiometers at three different locations extending from 37 to $67^{\circ} \mathrm{N}$ are used in this study. Ground-based microwave radiometry is a well-established remote sensing technique and has been used to study atmospheric phenomena such as sudden stratospheric warmings (e.g., Seele and Hartogh, 2000; Flury et al., 2009; Scheiben et al., 2012) and atmospheric tides (e.g., Haefele et al., 2008; Hallgren and Hartogh, 2012; Scheiben et al., 2013). Further, ground-based microwave radiometers are appropriate for calibration and validation of satellites and for monitoring of long-term trends of atmospheric composition (e.g., Nedoluha et al., 2003; Hartogh et al., 2011). To characterize the locally observed waves at the measurement locations on a global scale, satellite data from the Microwave Limb Sounder (MLS) on the Aura satellite are used.

The paper is structured in the following way. Section 2 describes the instruments and data sets used. Section 3 presents the methods used for deriving periodicities in the groundbased measurements and for characterizing the locally ob- served waves on a global scale with satellite data. Section 4 discusses the obtained results and in Sect. 5 follow the conclusions.

\section{Data}

Three ground-based microwave radiometers that are used for this study measure the pressure-broadened line emission of the rotational transition of water vapor at $22 \mathrm{GHz}$. The measured spectrum is inverted to a vertical profile of water vapor by the optimal estimation method (Rodgers, 2000) using the radiative transfer model ARTS2 and atmlab (Eriksson et al., 2011). The optimal estimation method requires a priori knowledge of the trace species to be retrieved. For all three radiometers used in this study, the a priori water vapor profiles are obtained from a monthly climatology of the years 2004 to 2007 of zonal mean water vapor measurements by the Microwave Limb Sounder on NASA's Aura satellite. All three radiometers are equipped with a fast Fourier transform spectrometer (FFTS). Water vapor is retrieved for the middle atmosphere between approximately 35 and $75 \mathrm{~km}$ altitude. The vertical observation range is limited by artifacts in the measured spectrum (baseline ripples) for the lower limit and by the measurement noise and the Doppler broadening for the upper limit. Data used for the analyses performed in this study are only considered if the measurement response of the retrieval is higher than 0.8 , corresponding to an a priori contribution smaller than 0.2 . The vertical resolution of the retrieved water vapor profiles (calculated as the full width at half maximum of the retrieved profiles) ranges from $12 \mathrm{~km}$ in the middle stratosphere to $17 \mathrm{~km}$ in the upper mesosphere.

The Seoul WAter vapor RAdiometer (SWARA) is located in Seoul, South Korea, at $126.9^{\circ} \mathrm{E} / 37.6^{\circ} \mathrm{N}$. It has been operating since November 2006 and is part of the Network for the Detection of Atmospheric Composition Change (NDACC). Water vapor is retrieved for altitudes between approximately 45 and $75 \mathrm{~km}$ (De Wachter et al., 2011). The lower observation limit is relatively high because strong baseline ripples in the measured spectrum do not allow a retrieval of the line wings, which contain information for altitudes below $45 \mathrm{~km}$. The bandwidth used is $80 \mathrm{MHz}$ at a spectral resolution of $60 \mathrm{kHz}$. The temporal resolution of the retrieval version used in this study varies with time, because the measured spectra are integrated until a measurement noise level of $0.01 \mathrm{~K}$ is reached, where the required integration time depends on the meteorological conditions in the troposphere. During the time period of interest, the temporal resolution varied between $1.5 \mathrm{~h}$ and 2 days.

The MIddle Atmospheric WAter vapor RAdiometer (MIAWARA) is located in Zimmerwald, near Bern, Switzerland, at $7.5^{\circ} \mathrm{E} / 47.9^{\circ} \mathrm{N}$ (Deuber et al., 2004). It was built in 2002 at the University of Bern and was moved to Zimmerwald in 2007 after a replacement of the spectrometer. It is also part of NDACC. The vertical observation range is from 
approximately 35 to $75 \mathrm{~km}$ altitude. The bandwidth used is $125 \mathrm{MHz}$ with a resolution of $60 \mathrm{kHz}$. The retrieval version used for this study has a fixed temporal resolution of 2 days. During the time period of interest, there are only 2 measurement gaps, one with a duration of 2 days, the other one with a duration of 4 days. MIAWARA and SWARA have a bias of less than $10 \%$ compared to the Microwave Limb Sounder on NASA's Aura satellite (Haefele et al., 2009).

MIAWARA-C was built in 2008 and was operated in Sodankylä, Finland, at $26.6^{\circ} \mathrm{E} / 67.4^{\circ} \mathrm{N}$ during the time period of interest for this study. It has a compact design and was built for measurement campaigns (Straub et al., 2010). The vertical observation range is from approximately 35 to $78 \mathrm{~km}$ altitude. The upper limit is higher than for the other radiometers because the spectral resolution of the FFTS of MIAWARA-C is $30 \mathrm{kHz}$ compared to the $60 \mathrm{kHz}$ of the other two radiometers. The bandwidth used for the retrieval is $125 \mathrm{MHz}$. The temporal resolution of the retrieval used for this study is 1 day, and during the whole time period of interest there are only four measurements gaps, with the largest gap being 5 days. MIAWARA-C has a bias of less than $10 \%$ compared to Aura MLS, except near the upper limit (in the upper mesosphere), where is has a dry bias of approximately $15 \%$ compared to Aura MLS (Tschanz et al., 2013).

The satellite data used in this study is obtained from the Microwave Limb Sounder on NASA's Aura satellite. The Aura satellite has a sun-synchronous orbit, and the MLS instrument measures atmospheric pressure, temperature, geopotential height and various trace species. For this study, the temperature, geopotential height and water vapor data from MLS (retrieval version v3.3) are used. MLS data are only considered within the valid vertical range and if the data are within the quality thresholds given by the data user guide of Aura MLS (http://mls.jpl.nasa.gov/data/datadocs. php).

In addition to observational data, wind and geopotential height data from the operational analysis of the European Centre for Medium-range Weather Forecast (ECMWF, http://www.ecmwf.int/en/forecasts/datasets) are used. The ECMWF model cycle used in this study is Cy37r3 and has 91 vertical levels from the surface up to $0.01 \mathrm{hPa}$. The wind data are used for the description of the SSW which occurred in mid-January 2012.

\section{Methods}

\subsection{Spectral analysis of ground-based observations}

To determine the dominant periods in the water vapor time series from our ground-based radiometers, a spectral analysis of the time series of the ground-based observations is performed. One approach for a spectral analysis of a time series is the Fourier transformation. However, a Fourier transformation requires an equally spaced time series. This is not the case for our ground-based observations of water vapor, since there are always days without measurements, e.g., during rainy days or during technical interruptions. A method that can handle nonuniformly spaced time series is a harmonic analysis with sinusoidal least-squares fits. Here, we use a sinusoidal least-squares fit including an offset and a linear term. Since the vertical water vapor profiles of our microwave radiometers are retrieved on a constant pressure grid, we process the data on every pressure grid point as individual time series. The least-squares spectral analysis is performed for periods from 4 to 28 days to capture the quasi 16-day wave and to check for dominant waves besides the quasi 16-day wave. For each period between 4 and 28 days with a spacing of 0.5 days, the sinusoidal least-squares fit is applied individually and the amplitude of the fitted sine wave determines the value of the spectral analysis for the given period and pressure level. The least-squares spectral analysis is performed for the whole time series during boreal winter 2011/2012, i.e., from 1 December 2011 to 31 March 2012.

\subsection{Bandpass filtering of ground-based observations}

To investigate the temporal evolution of the quasi 16-daywave, a bandpass filter is applied to the ground-based observations of mesospheric water vapor. A bandpass filter is used because the actual period of the quasi 16-day wave is not exactly 16 days, but varies between 12 and 20 days. Therefore, the bandpass filter was designed to suppress oscillations in the time series with periods shorter than 14 days and higher than 20 days. Fourteen days were chosen instead of 12 days at the lower cutoff period of the bandpass to minimize a potential influence of the 10-day wave, which is one of the normal modes according to Salby (1981a, b). The filter type is a finite impulse response (FIR) filter using a Hamming window whose size is 3 times the center period of the bandpass filter of 17 days, i.e., 51 days. The filtering is done with MATLAB using a zero-phase filter in both the forward and the reverse direction according to Oppenheim and Schafer (1989). This filter was described in a previous study on oscillations in atmospheric trace species (Studer et al., 2012).

\subsection{Space-time spectral analysis of satellite data}

Satellite data are used to characterize the observed waves in ground-based water vapor measurements. The classical approach to characterize planetary waves is the space-time Fourier analysis of a global data set along one latitude circle. The method proposed by Wu et al. (1995) is applied, which is explained in the following. Since satellite data do not have a regular sampling pattern and uniform spacing, methods using a discrete Fourier transformation cannot be used. Therefore, a least-squares fitting method is used for the spectral analysis of the satellite data in space and time. The spacetime spectral analysis is performed for the latitude circles of the ground-based instruments, i.e., at 37,47 and $67^{\circ} \mathrm{N}$, 
using a coincidence of $\pm 1^{\circ}$ in latitude. The resulting twodimensional satellite data are fitted to a model of the form

$$
y_{i}=A \cos \left[2 \pi\left(\frac{1}{T} t_{i}+s \lambda_{i}\right)\right]+B \sin \left[2 \pi\left(\frac{1}{T} t_{i}+s \lambda_{i}\right)\right],
$$

where the space-time series $y_{i}, i=1, \ldots, N$, are measured at UT $t_{i}$ and longitude $\lambda_{i} . T$ is the period, $s$ is the zonal wave number and $A$ and $B$ are the sinusoidal amplitudes. Negative values of $s$ denote eastward-traveling waves, while positive values denote westward-traveling waves. The wave amplitude is defined as $\sqrt{A^{2}+B^{2}}$ and is calculated for each wave number $s=-4, \ldots,+4$ and period $T=2, \ldots, 30$ days. The calculations were also performed for wave numbers larger than \pm 4 , but their amplitudes are too small. The results are presented as a two-dimensional periodogram showing the absolute wave amplitude for each wave number $s$ and period $T$.

\section{Results}

\subsection{Dominant oscillations in the local observations}

The spectral analysis of the water vapor time series from the three different measurement locations Sodankylä $\left(67^{\circ} \mathrm{N}\right)$, Bern $\left(47^{\circ} \mathrm{N}\right)$ and Seoul $\left(37^{\circ} \mathrm{N}\right)$ are shown in Fig. 1 in absolute wave amplitudes and in Fig. 2 in relative wave amplitudes. The relative amplitudes were calculated by dividing the absolute amplitudes by the average water vapor volume mixing ratio (VMR) within the considered time period at each pressure level. The spectral analysis was calculated according to the method described in Sect. 3.1 for the time period from 1 December 2011 to 31 March 2012. In Seoul (SWARA, lower panel), the wave activity in general is relatively low. There is one enhanced oscillation with a period of 15 days above $0.1 \mathrm{hPa}$ (approximately $64 \mathrm{~km}$ altitude). The amplitude of this oscillation is 0.2 parts per million (ppm) in water vapor VMR, which corresponds to approximately $5 \%$ in relative units. In the stratopause region between 1 and $0.3 \mathrm{hPa}$ where little or no gradients in water vapor exist, no wave activity is observed because water vapor can only be used as a tracer in regions with vertical and/or horizontal gradients in the water vapor VMR.

Looking at the spectral analysis obtained from MIAWARA (Bern, middle panel of Fig. 1), which is $10^{\circ}$ further north, a strong increase in wave activity compared to Seoul can be observed at various periods. The dominant oscillation above Bern is found above $0.1 \mathrm{hPa}$ and has a period of 15 to 16 days. This is equal to the dominant period at Seoul. However the amplitude of this dominant oscillation is twice as large $(0.4 \mathrm{ppm}$ or approximately $10 \%)$ as above Seoul. There are also relatively strong oscillations with periods between 10 and 11 days and between 18 and 20 days. Similar to Seoul, the wave activity in the stratopause region above Bern cannot be observed in water vapor because of the lack of water vapor gradients.

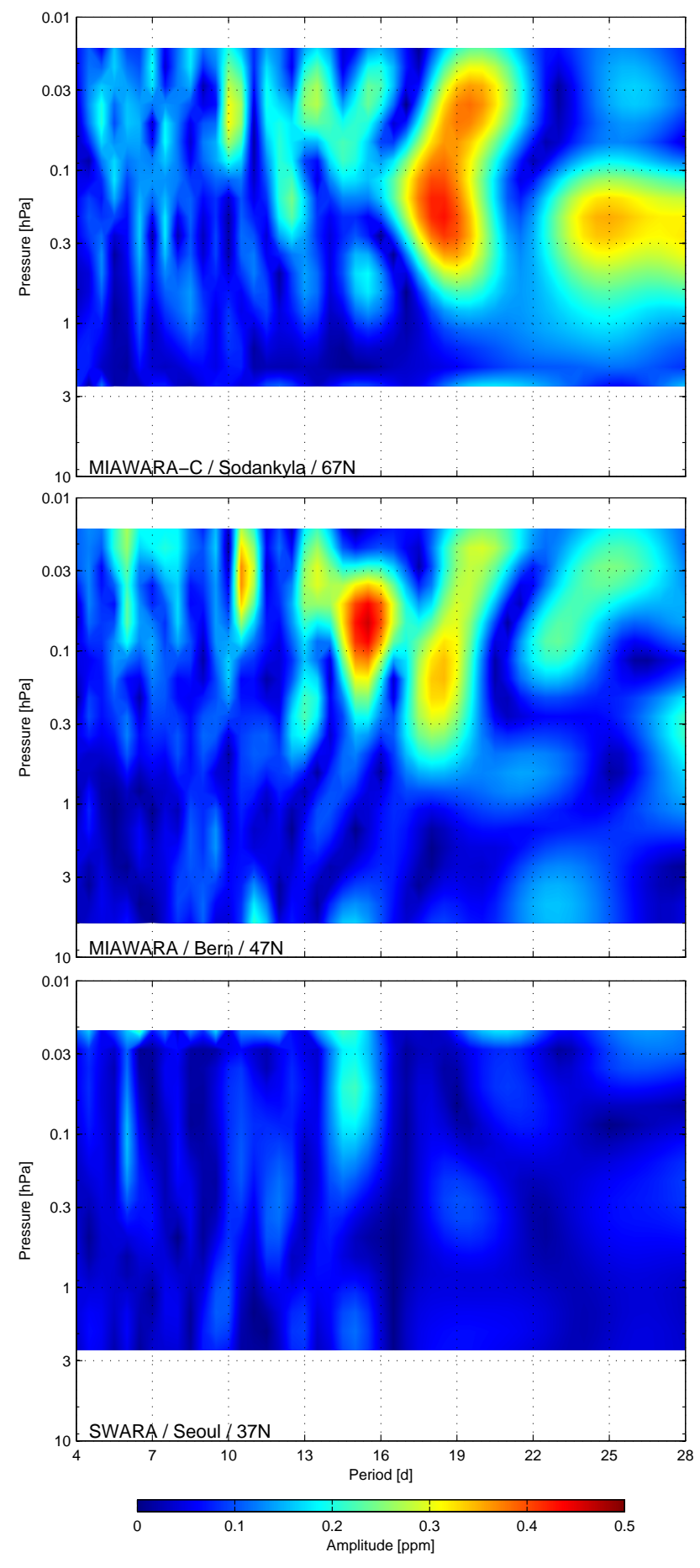

Figure 1. Average wave amplitudes from the spectral analysis of the water vapor measurements from the three ground-based microwave radiometers in Sodankylä, Bern and Seoul (from top to bottom) for the period from 1 December 2011 to 31 March 2012. See description within the text for details about the calculation method. 
The situation regarding the wave activity at the polar circle at Sodankylä (67 $\mathrm{N}$, upper panel in Fig. 1) is different compared to the midlatitude stations Seoul and Bern. The dominant oscillation above Sodankylä has a period of 18 to 20 days compared to 15 to 16 days at midlatitudes. The amplitude of this dominant wave above Sodankylä is approximately $0.4 \mathrm{ppm}$ and occurs between 0.3 and $0.03 \mathrm{hPa}$. Due to the decrease in water vapor VMR with altitude, this $0.4 \mathrm{ppm}$ wave amplitude corresponds to a relative amplitude that increases from approximately $5 \%$ at $0.3 \mathrm{hPa}$ to approximately $15 \%$ at $0.03 \mathrm{hPa}$. In contrast to the midlatitudinal station, wave activity in water vapor above Sodankylä can also be observed below $0.3 \mathrm{hPa}$. This reflects the fact that the height of the water vapor maximum is lower in the polar region than at midlatitudes due to the subsidence within the polar vortex. Hence there are water vapor gradients below $0.1 \mathrm{hPa}$, and therefore wave activity in polar water vapor can be observed at lower altitudes than at the midlatitudes. This dominant oscillation above Sodankylä with periods between 18 and 20 days is also visible above Bern and has a similar altitude dependence of the dominant period, such that the period of the oscillation increases with altitude from 18 days between 0.3 and $0.1 \mathrm{hPa}$ to 20 days at $0.03 \mathrm{hPa}$. Other relatively strong oscillations are observed with periods of 10 and 25 days.

Common for Bern and Sodankylä is the observed maximum of the absolute wave amplitudes between 0.3 and $0.03 \mathrm{hPa}$. This seems contradictory to theory that states that the amplitude of atmospheric waves generally increases with altitude due to the decrease in air density. The increase in absolute wave amplitude in water vapor is counterbalanced by the decrease in water vapor VMR in the upper mesosphere. Therefore, the increase in wave amplitude with altitude cannot be observed based on water vapor VMR in absolute wave amplitudes (Fig. 1). However when looking at the relative amplitudes (Fig. 2), the increase in wave amplitude with altitude becomes visible and the observational results are hence consistent with theory.

\subsection{Temporal evolution of the quasi 16-day wave}

In Fig. 1 the average wave amplitudes were shown over the whole winter 2011/2012 as a function of period and pressure level. In a next step, we look at the temporal evolution of the quasi 16-day wave at the three different measurement locations as derived from the consecutive 4-28-day periods the analysis was performed on. Therefore a bandpass filter for periods between 14 and 20 days is applied to our water vapor observations as described in Sect. 3.2. The results are shown in Fig. 3. The wave amplitudes vary strongly in time. At Seoul, the activity of the 16-day wave is generally lower than above Bern and Sodankylä. In the first half of January 2012, the wave activity above Seoul is reduced over the whole altitude range. The decrease in wave activity starts earlier in the mesosphere and later in the upper stratosphere.
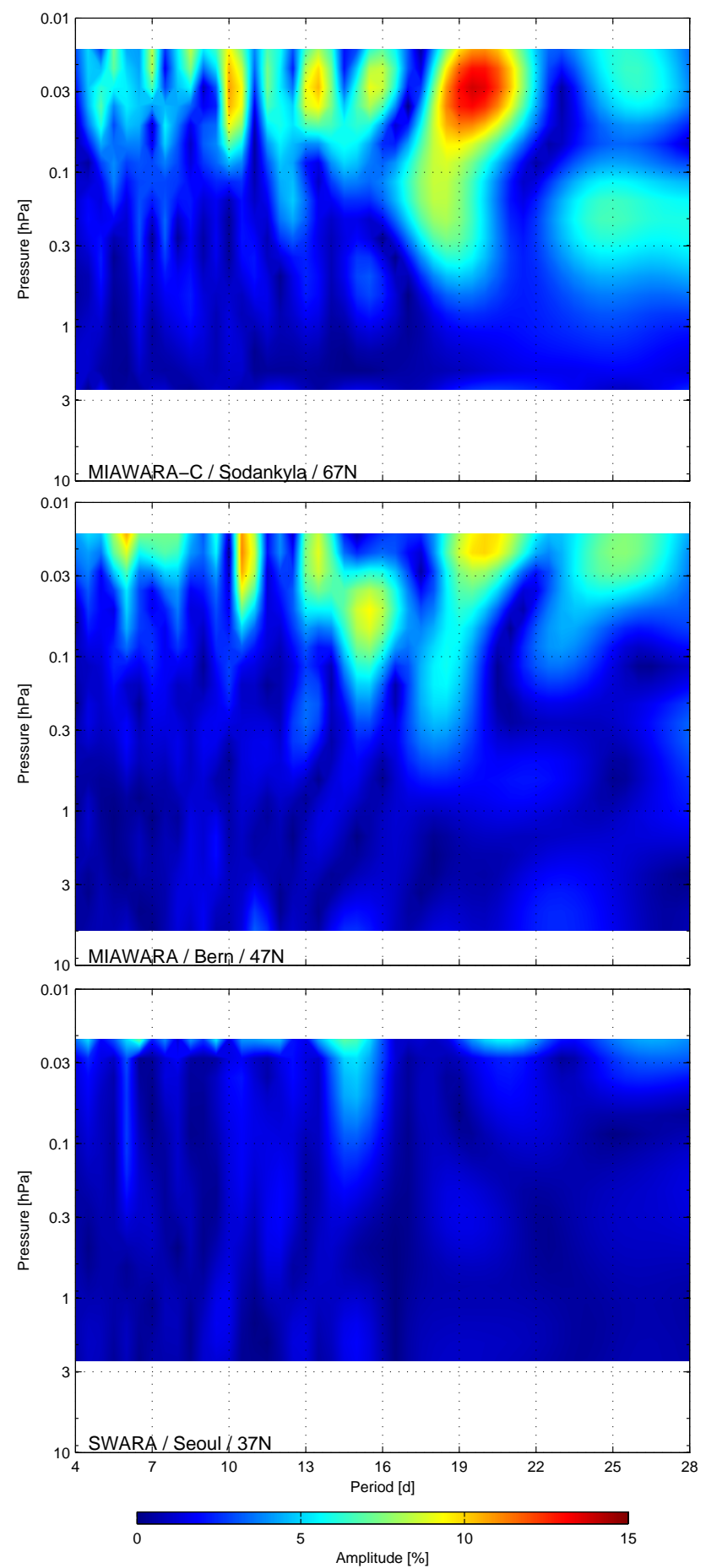

Figure 2. Analogous to Fig. 1, but showing the results as relative wave amplitudes. The relative amplitudes were calculated by dividing the absolute wave amplitudes from Fig. 1 by the average water vapor VMR within the considered time period at each pressure level. 

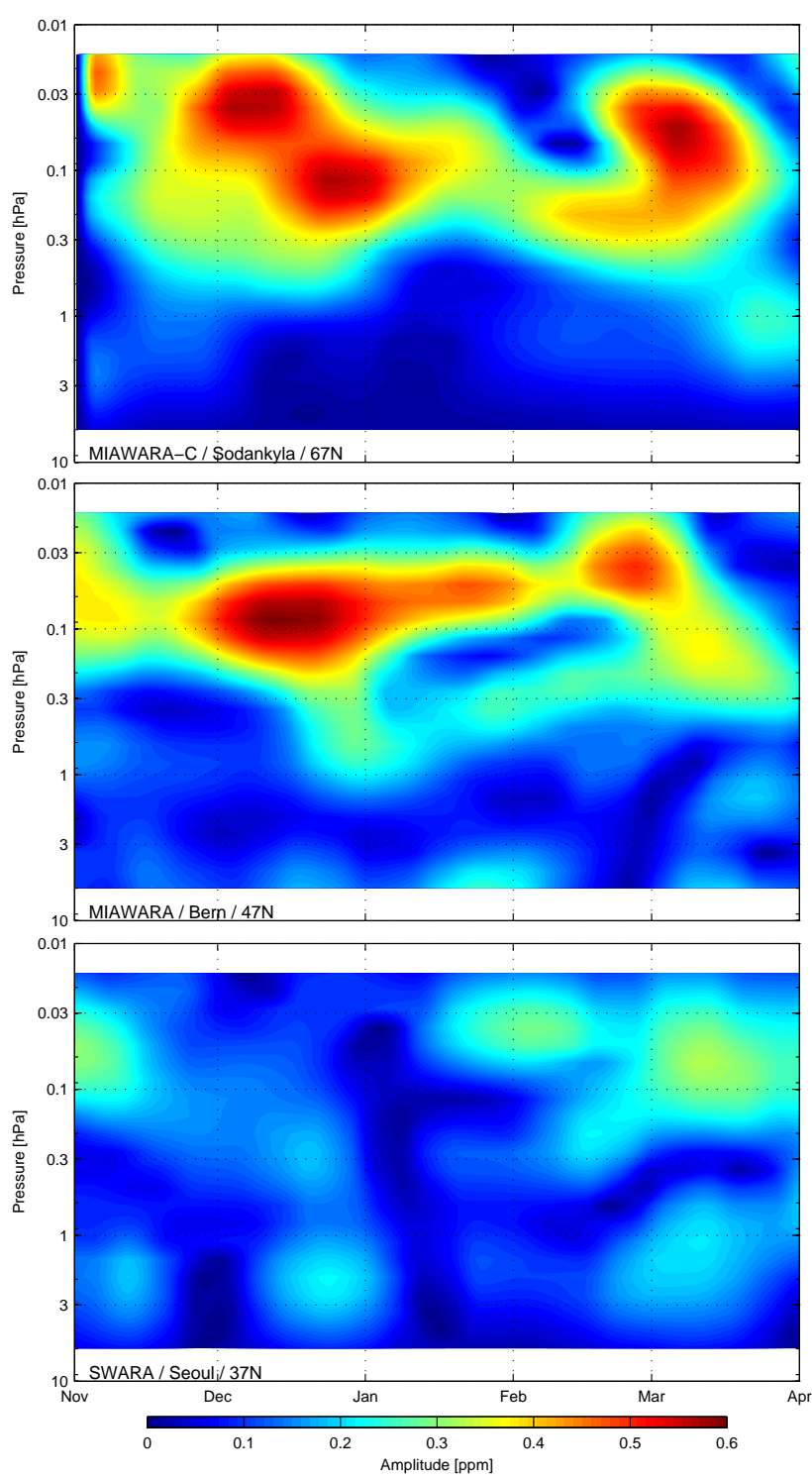

Figure 3. Amplitude of the bandpass-filtered water vapor time series as observed by the three ground-based microwave radiometers in Sodankylä, Bern and Seoul (from top to bottom). The lower and upper bandpass limits are 14 and 20 days, respectively. See description within the text for details about the calculation method.

Above Bern and Sodankylä, the 16-day wave increases in strength at the beginning of December 2011 and decreases again in early January 2012, coinciding with the wave activity decrease above Seoul. In mid-February 2012, the 16-day wave intensifies again and decreases towards the end of winter. It is again seen that the observable wave activity in water vapor VMR is strongly reduced in the stratopause region due to the lack of water vapor gradients.

A common observation at all three measurement locations is the decrease in mesospheric wave activity during January 2012. During this time, a SSW occurred and strongly affected middle-atmospheric dynamics in the Northern Hemisphere.
The effect of the SSW on the zonal mean temperature and the zonal mean zonal wind in the stratosphere and in the mesosphere is shown in Fig. 4. In the stratosphere $(10 \mathrm{hPa})$, the zonal mean temperature increased strongly within a few days in mid-January 2012, and the zonal mean zonal wind reversed from westward to eastward between 70 and $90^{\circ} \mathrm{N}$. According to the definition of a SSW by the Commission for Atmospheric Sciences of the World Meteorological Organization (WMO), this was not a major SSW because the wind reversal at $10 \mathrm{hPa}$ was not occurring at $60^{\circ} \mathrm{N}$. The onset of the SSW was on 14 January, 2012, which is the first day with a positive temperature gradient on $10 \mathrm{hPa}$ northward of $60^{\circ} \mathrm{N}$. Accompanying the warming in the stratosphere, there was a cooling in the mesosphere which is often observed during SSWs. The cooling in the mesosphere already started in the beginning of January and lasted until the end of the month. The zonal wind reversal also occurred in the mesosphere, was stronger than in the stratosphere and was occurring down to the midlatitudes at $50^{\circ} \mathrm{N}$. Before the SSW, the wave activity in our water vapor data increased. This behavior has been observed in previous studies, as mentioned in the Introduction section. The temporal coincidence of the decrease in wave activity in January 2012 and the SSW (in combination with a weakening of the polar vortex during the SSW) leads to the assumption that most observed wave activity is related to the polar vortex.

\subsection{A global perspective on the locally observed oscillations}

Based solely on the local observations of the quasi 16day wave, one cannot distinguish between eastward- and westward-traveling planetary waves, stationary planetary waves and standing waves. Further it is not possible to determine the zonal wave number of the locally observed oscillations. Therefore, satellite data from Aura MLS are used to characterize the observed waves. Fig. 5 shows the periodograms of the satellite observations of water vapor on the $0.05 \mathrm{hPa}$ pressure level at the latitude circles of our groundbased instruments $\left(67,47\right.$ and $\left.37^{\circ} \mathrm{N}\right)$. In addition to the water vapor data, we also show the periodogram of the geopotential height, which is often used to investigate the quasi 16-day wave. However it must be noted that waves in water vapor and geopotential height are not necessarily correlated, since waves observed at midlatitudinal mesospheric water vapor could originate from vertical and/or meridional displacement of air whereas the vertical and meridional gradients of water vapor and geopotential height can be very different.

The dominant oscillation on $0.05 \mathrm{hPa}$ that was observed with the ground-based radiometer in Seoul has a period of 15 days. However in the periodogram at the latitude circle of Seoul $\left(37^{\circ} \mathrm{N}\right.$, Fig. 5, lower panel), the dominant wave is $T=$ $20, s=1$ (i.e., westward traveling with wave number 1 and a period of 20 days) and has an amplitude of approximately $0.2 \mathrm{ppm}$. Another relatively strong oscillation is $T=16, s=$ 

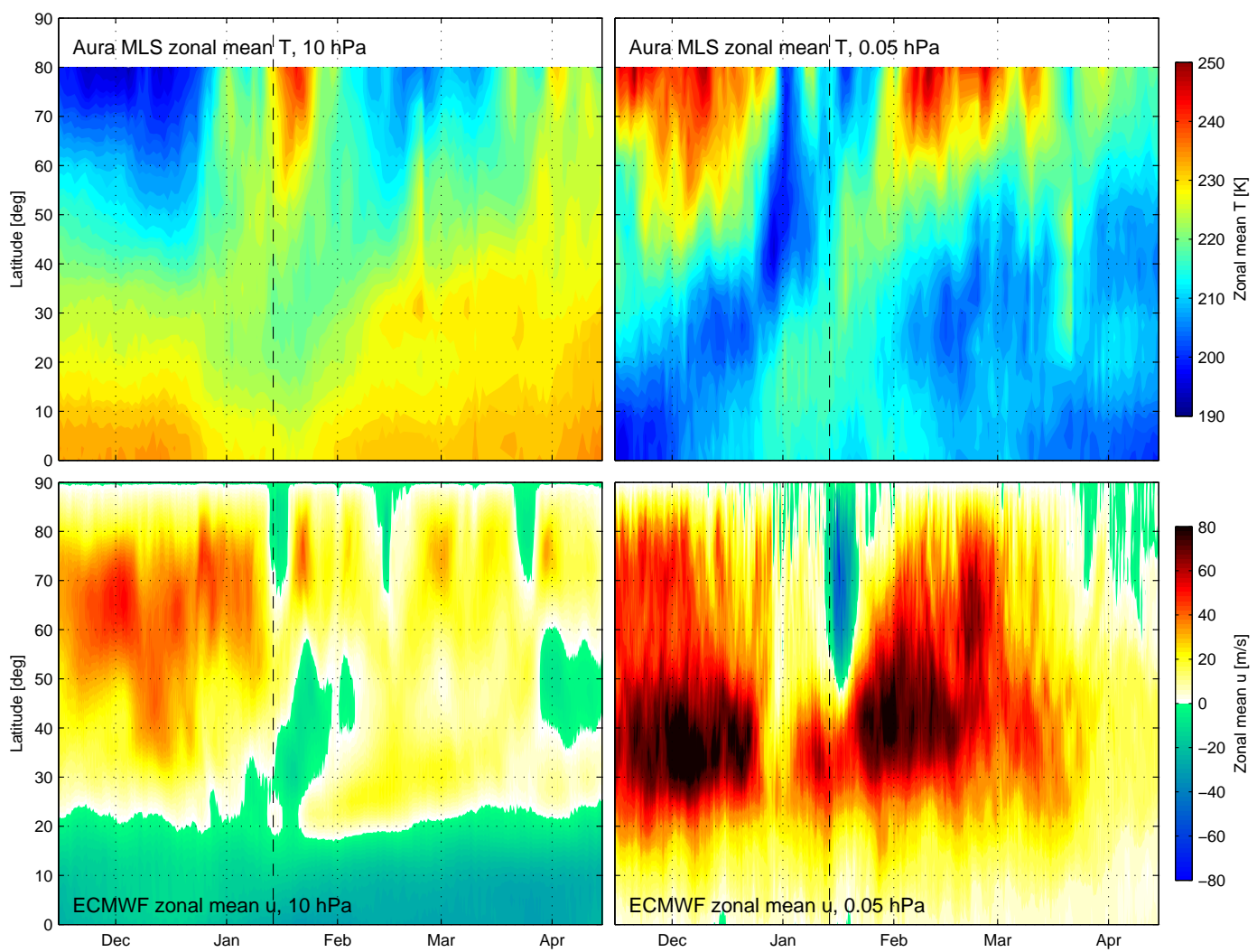

Figure 4. Zonal mean Aura MLS temperature (top panels) and ECMWF zonal wind (bottom panels) on $10 \mathrm{hPa}$ (left panels) and $0.05 \mathrm{hPa}$ (right panels) during boreal winter 2011/2012. The black dashed lines indicate the beginning of the SSW on 14 January 2012.

-1 (i.e., eastward traveling with wave number 1 and a period of 16 days). The absence of the locally observed oscillation at 15 days in the zonal mean and the presence of the 16and 20-day-waves as seen in the zonal mean, but not locally above Seoul, indicates a longitudinally varying amplitude of these waves. The longitudinal dependence will be discussed later. The westward-traveling 20-day wave is also observed in geopotential height. However, the eastward-traveling 16day wave as observed in water vapor is absent in geopotential height. In fact, all eastward-traveling and stationary waves are absent in the geopotential height field at $37^{\circ} \mathrm{N}$.

Above Bern, the dominant oscillation at $0.05 \mathrm{hPa}$ has a period of 15.5 days (Fig. 1, middle panel). Other relatively strong oscillations above Bern on $0.05 \mathrm{hPa}$ are observed with periods of 11 and 20 days. These oscillations are also seen in the zonal mean at $47^{\circ} \mathrm{N}$ (Fig. 5, middle panel). These three oscillations have zonal wave number 1 where the 11- and the 15.5-day waves are eastward traveling and the 20-day wave is westward traveling. However, the 20-day wave is stronger than the 15.5-day wave in the zonal mean, whereas the opposite is the case locally above Bern. In geopotential height, only the westward-traveling 20-day wave is present, similar to the situation at the latitude of Seoul $\left(37^{\circ} \mathrm{N}\right)$.

In the polar region (at $67^{\circ} \mathrm{N}$, Fig. 5, upper panel), the dominant wave is also the westward-traveling 20-day wave with zonal wave number 1, like at midlatitudes. However, this 20day wave also has a strong eastward-traveling component. This combination of two waves with the same period traveling in opposite directions results in a standing wave with two nodes around the latitude circle. This is shown further below in the discussion of the longitudinal dependence of the observed waves. In the local observations at Sodankylä on $0.05 \mathrm{hPa}$, the dominant oscillation has a period between 18 and 20 days, which is consistent with the zonal mean results. Oscillations of minor importance within the range of the quasi 16-day wave have periods of 13 and 15.5 days, and they appear both locally and in the zonal mean. The zonal mean waves in geopotential height in the polar mesosphere are different to the waves in water vapor. The strong waves in water vapor with periods of 20,15.5 and 13 days do not appear in geopotential height. The dominant wave in geopotential height has a period between 24 and 28 days. Within the range of the quasi 16-day wave, a wave with a period of 18 days is found in geopotential height, but not in water vapor. Also, the situation in the polar region is different to the one at midlatitudes. The westward-traveling 20-day wave that is present in the geopotential height data from the midlatitudinal mesosphere does not exist at $67^{\circ} \mathrm{N}$. 

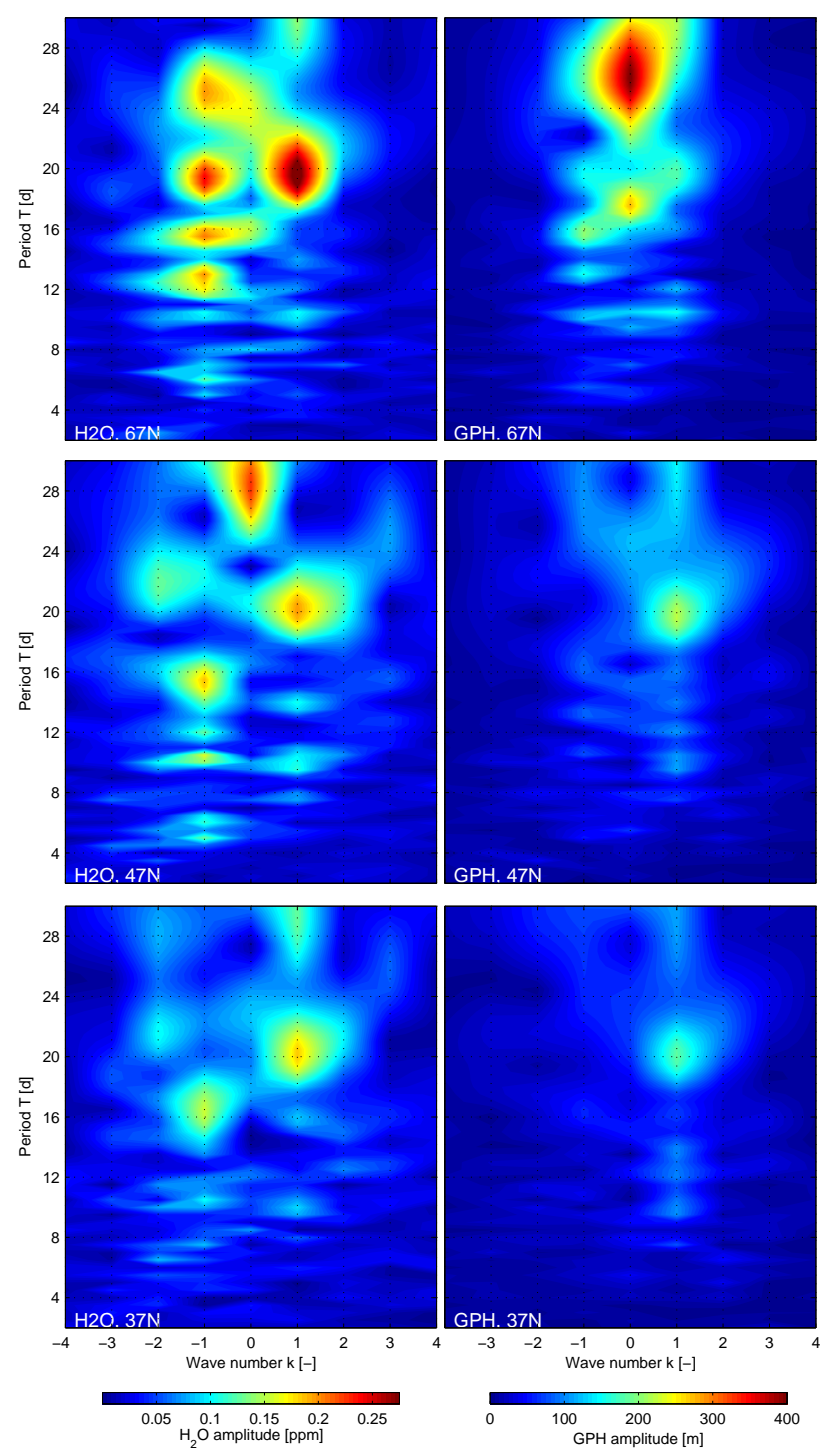

Figure 5. Periodogram for traveling and stationary planetary waves in water vapor (left panels) and geopotential height (right panels) on $0.05 \mathrm{hPa}$ (approximately $70 \mathrm{~km}$ ) as observed by Aura MLS at the latitudes of the ground-based microwave radiometers $(67,47$ and $37^{\circ} \mathrm{N}$, from top to bottom) during boreal winter 2011/2012.

\subsection{Longitudinal variation of the quasi 16-day wave}

In Fig. 5 the zonal mean planetary waves at the latitude circles of our ground-based radiometers were shown. Certain observed features in the ground-based data could be explained with the zonal mean data set. However, certain inconsistencies between the local and the zonal mean data sets remain, such as the absence of strong oscillations locally at Seoul in contrast to the zonal average at $37^{\circ} \mathrm{N}$ or the dominant oscillation with a period of 16 days at Bern in contrast to the dominant wave with a period of 20 days in the zonal mean data. To explain these remaining inconsistencies, the longitudinal variations of the wave amplitudes with periods

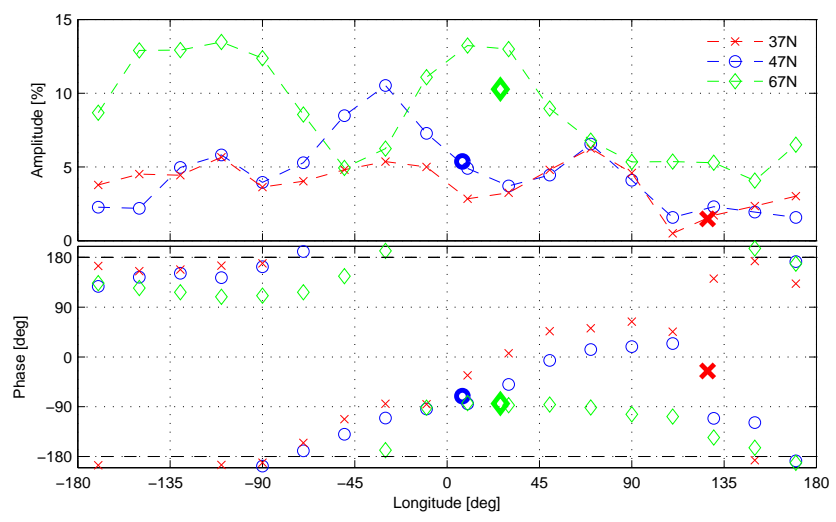

Figure 6. Amplitudes (top panel) and phase (bottom panel) of the 20-day wave in water vapor on $0.05 \mathrm{hPa}$ as observed by Aura MLS and the three ground-based microwave radiometers during boreal winter 2011/2012. The bold symbols are from the ground-based radiometers (Bern at $7.5^{\circ} \mathrm{E}$, Sodankylä at $26.6^{\circ} \mathrm{E}$ and Seoul at $127^{\circ} \mathrm{E}$ ), and the thin symbols connected with dashed lines are from Aura MLS at the latitudes of the ground-based microwave radiometers $\left(37^{\circ} \mathrm{N}\right.$ for Seoul, $47^{\circ} \mathrm{N}$ for Bern and $67^{\circ} \mathrm{N}$ for Sodankylä).

of 20 days and 16 days are shown in Figs. 6 and 7, respectively, based on Aura MLS water vapor data. Aura MLS data have been averaged into bins of $20^{\circ}$ longitude and $2^{\circ}$ latitude, where the central latitude corresponds to the latitudes of the three ground-based measurement locations. The upper panels of the figures show the longitudinal dependence of the amplitude of oscillations in water vapor on $0.05 \mathrm{hPa}$ as observed by Aura MLS at the latitude circles of our groundbased instruments. The lower panels show the phase in time with respect to 1 December 2011. In addition, the amplitudes and phases from the ground-based observations are shown at the corresponding longitudes. The data from Aura MLS on $0.05 \mathrm{hPa}$ have a relatively coarse vertical resolution that is only slightly better than the vertical resolution from the ground-based microwave radiometers. Therefore a convolution of the satellite data with the averaging kernels of the ground-based instruments is not required for the data analysis. To check whether this statement holds true in our case, convolution tests have been performed where the following figures showing satellite data have also been created with convolved satellite data sets. This led to very similar results to those in the figures with the unconvolved (original) satellite data.

In the previous section it was shown that the 20-day wave on $0.05 \mathrm{hPa}$ is present in the zonal mean at the latitude circle of Seoul, but not locally above Seoul. This is not an inconsistency since Fig. 6 shows that the 20-day wave at $37^{\circ} \mathrm{N}$ diminishes between 90 and $180^{\circ} \mathrm{E}$, i.e., at the longitude of Seoul. For the latitude of Bern, the 20-day wave in water vapor on $0.05 \mathrm{hPa}$ is strongest at approximately $30^{\circ} \mathrm{W}$ with a relative amplitude of $10 \%$ and has two other maxima at 


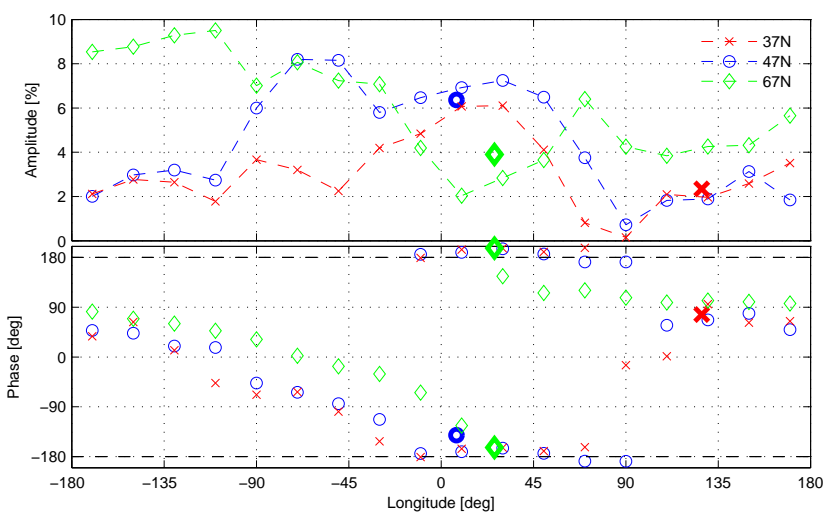

Figure 7. Analogous to Fig. 6 but for the 16-day wave.

$110^{\circ} \mathrm{W}$ and $70^{\circ} \mathrm{E}$. The longitudinal variations and the phase of the 20-day wave at the latitude circles of Seoul and Bern are similar, indicating that the 20-day wave is a large-scale wave affecting a broad range of latitudes. At $67^{\circ} \mathrm{N}$, there are two maxima with a relative amplitude of approximately $14 \%$ between 150 and $90^{\circ} \mathrm{W}$ and between 0 and $30^{\circ} \mathrm{E}$. These two maxima are consistent with the discussion in the previous section, where we stated that the 20-day wave in the polar region consists in two waves traveling in opposite directions, which leads to a standing wave. Hence, the phase of the polar 20-day wave does not exhibit a clear eastward- or westwardtraveling pattern like at midlatitudes, but shows two distinct regions with two different phases. The wave amplitudes obtained by the ground-based observations are similar to the ones obtained by the satellite data. However, the phases are only similar between ground-based and satellite data for MIAWARA (Bern) and MIAWARA-C (Sodankylä) and not for SWARA (Seoul). The 20-day wave observed with SWARA is approximately $180^{\circ}$ out of phase compared to the one observed by Aura MLS. We assume that this discrepancy is due to the fact that it is difficult to adequately determine the phase of the very weak 20-day wave above Seoul (amplitude less than $2 \%$ ) that is superposed by measurement noise.

The longitudinal variations of the 16-day wave are shown in Fig. 7. As for the 20-day wave, the 16-day wave at 37 and $47^{\circ} \mathrm{N}$ are similar with respect to longitudinal variations in amplitude and phase. The 16-day wave maximizes between $30^{\circ} \mathrm{W}$ and $45^{\circ} \mathrm{E}$ at $37^{\circ} \mathrm{N}$ and between $90^{\circ} \mathrm{W}$ and $45^{\circ} \mathrm{E}$ at $47^{\circ} \mathrm{N}$ with relative amplitude of up to $8 \%$. In the polar region, the 16-day wave minimizes between $30^{\circ} \mathrm{W}$ and $45^{\circ} \mathrm{E}$, i.e., at the longitude where the wave has a maximum at midlatitudes. For all three latitude circles, the 16-day wave is eastward propagating with zonal wave number 1 . The amplitude and phase obtained by the ground-based and the satellite data are consistent.

To conclude, a hemispheric map shows the amplitude of the quasi 16-day wave on $0.05 \mathrm{hPa}$ during boreal winter 2011/2012 in Fig. 8. The amplitude is obtained by bandpassfiltering the Aura MLS data and averaging the amplitudes over the whole winter. The results are shown for water vapor (left panel) and geopotential height (right panel). Additionally, the wintertime average of the geopotential height field from ECMWF on $0.05 \mathrm{hPa}$ is shown by the black contour lines with the lowest values in the northern part of Greenland. Although we believe that the ECMWF geopotential height fields at $0.05 \mathrm{hPa}$ are a good approximative representation of the mesospheric polar vortex, it needs to be noted that the ECMWF fields in the mesosphere are essentially not constrained to observational data and therefore need to be analyzed with care.

In both water vapor and geopotential height, the quasi 16day wave maximizes over northern Europe and the polar region of North America, except for the region of Greenland where only small amplitudes are observed. The wave minimizes over central and eastern Asia. The maximum amplitude in water vapor is $0.5 \mathrm{ppm}$ (approximately $15 \%$ ) and $500 \mathrm{~m}$ in geopotential height. The contour lines of the average geopotential height field indicate the position of the average wintertime polar vortex and show that the vortex was located slightly off-pole with the vortex centered above the northern part of Greenland. The highest quasi 16-day wave amplitudes in water vapor and geopotential height are found around the center of the mesospheric vortex, but not directly in the center of the vortex.

The asymmetric longitudinal distribution of the quasi 16day wave implies that the classical approach for the characterization of planetary waves by wave number and traveling direction along one latitude circle is not sufficient to explain the local observations. The position of the wave amplitude maximum seems to be related to the center of the polar vortex as indicated by the average geopotential height field. Therefore, characterizing the planetary waves along equivalent latitude circles that are related to the center of the polar vortex instead of geographical latitude circles could increase the quality of the analysis. A similar finding was obtained by a study from Hocke et al. (2013) for a standing wave of the polar vortex in the northern winter stratosphere. Based on ozone observations and ECMWF reanalysis data, they also found a strong longitudinal variation of the wave amplitude along geographical latitude circles.

\section{Summary}

We have shown observations of the quasi 16-day wave in mesospheric water vapor during boreal winter 2011/2012 obtained by ground-based microwave radiometers and complemented by satellite data. The ground-based and satellite data agree well with each other both in amplitude and phase of the quasi 16-day wave. A SSW that occurred in January 2012 was preceded by strong wave activity and led to a decrease in wave activity during the SSW. The observed quasi 16-day wave at the two midlatitudinal measurement locations is a combination of a westward-traveling wave number 1 wave 

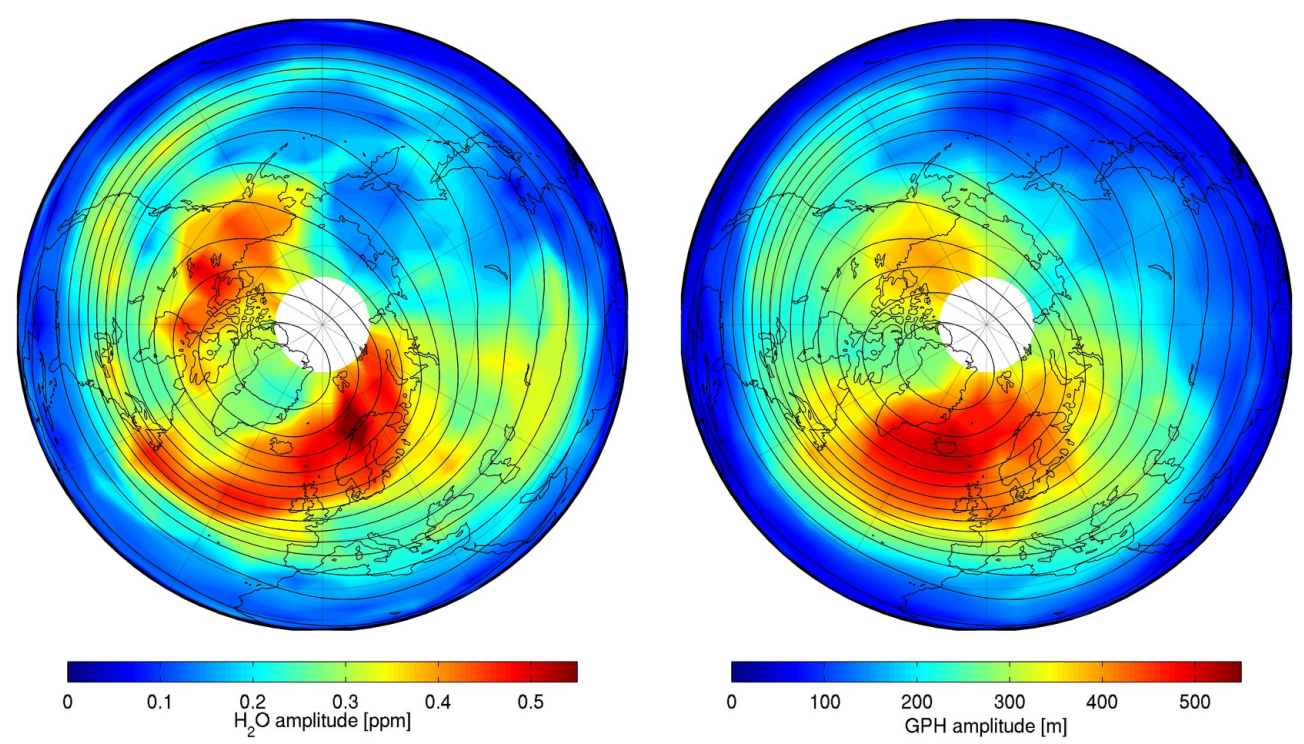

Figure 8. Hemispheric map of the amplitude of the quasi-16-day wave in water vapor (left panel) and geopotential height (right panel) on $0.05 \mathrm{hPa}$ as observed by Aura MLS during boreal winter 2011/2012. The amplitude is obtained by averaging the wave amplitude of the bandpass-filtered water vapor and geopotential height time series with a bandpass range from 14 to 20 days. The contour lines represent the average geopotential height on $0.05 \mathrm{hPa}$ between 1 December 2011 and 31 March 2012. The contour lines are equally spaced.

with a period of 20 days and an eastward-traveling wave number 1 wave with a period of 16 days. In the polar region, two dominant waves with a period of 20 days traveling in opposite directions result in a standing wave, with Sodankylä being located in one of two antinodes. It was shown that the waves have a strong longitudinal variation along one latitude circle, which explains the differences between the zonal mean perspective and the local ground-based observations. The quasi 16-day wave in mesospheric water vapor maximizes over northern Europe and the polar region of North America. From a hemispheric perspective, the region of the highest quasi 16-day wave activity in water vapor is very similar to the wave activity in geopotential height.

We find that the classical approach for the characterization of planetary waves by wave number and traveling direction along one latitude circle is not sufficient to explain the local observations. It fails in the present study during boreal winter 2011/2012 because of a strong longitudinal dependence of the observed wave amplitudes. The region of highest wave activity seems to be related to the center of the polar vortex. A characterization of planetary waves along equivalent latitude circles instead of geographical latitude circles as in the classical approach would presumably decrease the differences between the zonal mean perspective and the local observations of planetary waves.
Acknowledgements. This work has been funded by the Swiss National Science Foundation under grant 200020-146388 and MeteoSwiss in the frame of the project MIMAH. The study is further supported by the Strategic Korean-Swiss Cooperative Program. We acknowledge NASA for the data access to the Aura MLS measurements. We thank the team of the Finnish Weather Service for their hospitality and support during the campaign. We further thank the two referees whose feedback during the review process helped to improve this study.

Edited by: G. Stiller

\section{References}

Andrews, D. G., Holton, J. R., and Leovy, C. B.: Middle atmosphere dynamics, Academic, San Diego, CA, 1987.

Charney, J. G. and Drazin, P. G.: Propagation of planetary-scale disturbances from lower into upper atmosphere, J. Geophys. Res., 66, 83-109, doi:10.1029/JZ066i001p00083, 1961.

Day, K. A. and Mitchell, N. J.: The 16-day wave in the Arctic and Antarctic mesosphere and lower thermosphere, Atmos. Chem. Phys., 10, 1461-1472, doi:10.5194/acp-10-1461-2010, 2010.

Day, K. A., Hibbins, R. E., and Mitchell, N. J.: Aura MLS observations of the westward-propagating $s=1$, 16-day planetary wave in the stratosphere, mesosphere and lower thermosphere, Atmos. Chem. Phys., 11, 4149-4161, doi:10.5194/acp-11-41492011, 2011.

De Wachter, E., Haefele, A., Kämpfer, N., Ka, S., Lee, J. E., and Oh, J. J.: The Seoul Vapour Radiometer for the Middle Atmosphere: Calibration, Retrieval and Validation, IEEE T. Geosci. Remote, 49, 1052-1062, doi:10.1109/TGRS.2010.2072932, 2011. 
Deuber, B., Kämpfer, N., and Feist, D. G.: A new 22$\mathrm{GHz}$ radiometer for middle atmospheric water vapor profile measurements, IEEE T. Geosci. Remote, 42, 974-984, doi:10.1109/TGRS.2004.825581, 2004.

Eriksson, P., Buehler, S. A., Davis, C. P., Emde, C., and Lemke, O.: ARTS, the atmospheric radiative transfer simulatur, version 2, J. Quant. Spectrosc. Ra., 112, 1551-1558, 2011.

Espy, P. J., Stegman, J., and Witt, G.: Interannual variations of the quasi-6-day oscillation in the polar summer mesospheric temperature, J. Geophys. Res., 102, 1983-1990, 1997.

Flury, T., Hocke, K., Haefele, A., Kämpfer, N., and Lehmann, R.: Ozone depletion, water vapor increase, and PSC generation at midlatitudes by the 2008 major stratospheric warming, J. Geophys. Res., 114, D18302, doi:10.1029/2009JD011940, 2009.

Forbes, J. M., Hagan, M. E., Miyahara, S., Vial, F., Mason, A. H., Meek, C. E., and Portnyagin, Y. I.: Quasi 16-day oscillation in the mesosphere and lower thermosphere, J. Geophys. Res., 100, 9149-9163, 1995.

Forbes, J. M., Zhang, X., Ward, W., and Talaat, E. R.: Climatological features of mesosphere and lower thermosphere stationary planetary waves within \pm 40 latitude, J. Geophys. Res., 107, 4322, doi:10.1029/2001JD001232, 2002.

Haefele, A., Hocke, K., Kämpfer, N., Keckhut, P., Marchand, M., Bekki, S., Morel, B., Egorova, T., and Rozanov, E.: Diurnal changes in middle atmospheric $\mathrm{H}(2) \mathrm{O}$ and $\mathrm{O}(3)$ : Observations in the Alpine region and climate models, J. Geophys. Res., 113, D17303, doi:10.1029/2008JD009892, 2008.

Haefele, A., De Wachter, E., Hocke, K., Kämpfer, N., Nedoluha, G. E., Gomez, R. M., Eriksson, P., Forkman, P., Lambert, A., and Schwartz, M. J.: Validation of ground based microwave radiometers at $22 \mathrm{GHz}$ for stratospheric and mesospheric water vapor, J. Geophys. Res., 114, D23305, doi:10.1029/2009JD011997, 2009.

Hallgren, K. and Hartogh, P.: First detection of tidal behaviour in polar mesospheric water vapour by ground based microwave spectroscopy, Atmos. Chem. Phys., 12, 3753-3759, doi:10.5194/acp-12-3753-2012, 2012.

Hartogh, P., Sonnemann, G. R., Grygalashvyly, M., and Jarchow, C.: Ozone trends in the mid-latitude stratopause region based on microwave measurements at Lindau (51.66 degrees N, 10.13 degrees E), the ozone reference model, and model calculations, Adv. Space Res., 47, 1937-1948, doi:10.1016/j.asr.2011.01.010, 2011.

Hirota, I., Kuroi, K., and Shiotani, M.: Midwinter warmings in the Southern hemisphere stratosphere in 1988, Q. J. Roy. Meteor. Soc., 116, 929-941, 1990.

Hocke, K., Studer, S., Martius, O., Scheiben, D., and Kämpfer, N.: A 20-day period standing oscillation in the northern winter stratosphere, Ann. Geophys., 31, 755-764, doi:10.5194/angeo31-755-2013, 2013.

Jacobi, C., Kürschner, D., Muller, H. G., Pancheva, D., Mitchell, N. J., and Naujokat, B.: Response of the mesopause region dynamics to the February 2001 stratospheric warming., J. Atmos. Sol.-Terr. Phy., 65, 843-855, 2003.

Krüger, K., Naujokat, B., and Labitzke, K.: The unusual mid-winter warming in the Southern Hemisphere 2002: A comparison to Northern Hemisphere phenomena, J. Atmos. Sci., 62, 603-613, 2005.

Luo, Y., Manson, A. H., Meek, C. E., Meyer, C. K., and Forbes, J. M.: The quasi 16-day oscillation in the mesosphere and lower thermosphere at Saskatoon $\left(52^{\circ} \mathrm{N}, 107^{\circ} \mathrm{W}\right), 1980-1996$, J. Geophys. Res., 195, 2125-2138, 2000.

Matsuno, T.: Dynamical model of stratospheric sudden warming, J. Atmos. Sci., 28, 1479-1494, 1971.

Mitchell, N. J., Middleton, H. R., Beard, A. G., Williams, P. J. S., and Muller, H. G.: The 16-day planetary wave in the mesosphere and lower thermosphere, Ann. Geophys., 17, 1447-1456, doi:10.1007/s00585-999-1447-9, 1999.

Nedoluha, G., Bevilacqua, R., Gomez, R., Hicks, B., Russell, J., and Connor, B.: An evaluation of trends in middle atmospheric water vapor as measured by HALOE, WVMS, and POAM, J. Geophys Res., 108, 4391, doi:10.1029/2002JD003332, 2003.

Oppenheim, A. V. and Schafer, R. W.: Discrete-Time Signal Processing, Prentice-Hall, New Jersey, 1989.

Palo, S. E., Forbes, J. M., Zhang, X., Russell, J. M., Mertens, C. J., Mlynczak, M. G., Burns, G. B., Espy, P. J., and Kawahara, T. D.: Planetary wave coupling from the stratosphere to the thermosphere during the 2002 Southern Hemisphere pre-stratwarm period, Geophys. Res. Lett., 32, L23809, doi:10.1029/2005GL024298, 2005.

Pancheva, D. and Mukhtarov, P.: Atmospheric Tides and Planetary Waves: Recent Progress Based on SABER/TIMED Temperature Measurements (2002-2007), chap. 2, Aeronomy of the Earth's Atmosphere and Ionosphere, 19-56, Springer, Dordrecht, 2011.

Pancheva, D., Mukhtarov, P., Mitchell, N. J., Andonov, B., Merzlyakov, E., Singer, W., Murayama, Y., Kawamura, S., Xiong, J., Wan, W., Hocking, W., Fritts, D., Riggin, D., Meek, C., and Manson, A.: Latitudinal wave coupling of the stratosphere and mesosphere during the major stratospheric warming in 2003/2004, Ann. Geophys., 26, 467-483, doi:10.5194/angeo-26-467-2008, 2008a.

Pancheva, D., Mukhtarov, P., Mitchell, N. J., Merzlyakov, E., Smith, A. K., Andonov, B., Singer, W., Hocking, W., Meek, C., Manson, A., and Murayama, Y.: Planetary waves in coupling the stratosphere and mesosphere during the major stratospheric warming in 2003/2004, J. Geophys. Res., 113, D12105, doi:10.1029/2007JD009011, 2008b.

Rodgers, C. D.: Inverse Methods for Atmospheric Soundings, World Scientific Publishing Co Pte. Ltd, Singapore, 2000.

Salby, M. L.: Rossby normal-modes in nonuniform background configurations. Part I: Simple fields, J. Atmos. Sci., 38, 1803-1826, doi:10.1175/15200469(1981)038<1803:RNMINB > 2.0.CO;2, 1981a.

Salby, M. L.: Rossby normal-modes in nonuniform background configurations. Part II: Equinox and solstice conditions, J. Atmos. Sci., 38, 1827-1840, doi:10.1175/15200469(1981)038<1827:RNMINB>2.0.CO;2, 1981 b.

Scheiben, D., Straub, C., Hocke, K., Forkman, P., and Kämpfer, N.: Observations of middle atmospheric $\mathrm{H}_{2} \mathrm{O}$ and $\mathrm{O}_{3}$ during the 2010 major sudden stratospheric warming by a network of microwave radiometers, Atmos. Chem. Phys., 12, 7753-7765, doi:10.5194/acp-12-7753-2012, 2012.

Scheiben, D., Schanz, A., Tschanz, B., and Kämpfer, N.: Diurnal variations in middle-atmospheric water vapor by ground-based microwave radiometry, Atmos. Chem. Phys., 13, 6877-6886, doi:10.5194/acp-13-6877-2013, 2013.

Seele, C. and Hartogh, P.: A case study on middle atmospheric water vapor transport during the February 1998 stratospheric warming, Geophys. Res. Lett., 27, 3309-3312, 2000. 
Shepherd, M. G., Wu, D. L., Fedulina, I. N., Gurubaran, S., Russell, J. M., Mlynczak, M. G., and Shepherd, G. G.: Stratospheric warming effects on the tropical mesospheric temperature field, J. Atmos. Sol.-Terr. Phy., 69, 2309-2337, 2007.

Sivjee, G. G., Walterscheid, R. L., and McEwen, D. J.: Planetary wave disturbances in the arctic winter mesopause over Eureka $\left(80^{\circ} \mathrm{N}\right)$, Planet. Space Sci., 42, 973-986, 1994.

Smith, A. K.: Longitudinal variations in mesospheric winds: Evidence for gravity wave filtering by planetary waves, J. Atmos. Sci., 53, 1156-1173, 1996.

Smith, A. K.: The origin of stationary planetary waves in the upper mesosphere, J. Atmos. Sci., 60, 3033-3041, 2003.

Straub, C., Murk, A., and Kämpfer, N.: MIAWARA-C, a new ground based water vapor radiometer for measurement campaigns, Atmos. Meas. Tech., 3, 1271-1285, doi:10.5194/amt-31271-2010, 2010.
Studer, S., Hocke, K., and Kämpfer, N.: Intraseasonal oscillations of stratospheric ozone above Switzerland, J. Atmos. Sol.-Terr. Phy., 74, 189-198, doi:10.1016/j.jastp.2011.10.020, 2012.

Tschanz, B., Straub, C., Scheiben, D., Walker, K. A., Stiller, G. P., and Kämpfer, N.: Validation of middle-atmospheric campaignbased water vapour measured by the ground-based microwave radiometer MIAWARA-C, Atmos. Meas. Tech., 6, 1725-1745, doi:10.5194/amt-6-1725-2013, 2013.

Wu, D. L., Hays, P. B., and Skinner, W. R.: A Least Squares Method for Spectral Analysis of Space-Time Series, J. Atmos. Sci., 52, 3501-3511, doi:10.1175/15200469(1995)052<3501:ALSMFS>2.0.CO;2, 1995. 